\title{
A RETROSPECTIVE STUDY OF MATERNAL MORTALITY DUE TO POSTPARTUM HAEMORRHAGE OVER THE PERIOD OF LAST 10 YEARS IN A TERTIARY CARE CENTRE
}

\author{
Sonal Kulshreshtha1, Pratibha Garg², Deepika Dhurvey³
}

${ }_{1}^{1}$ Associate Professor, Department of Obstetrics and Gynaecology, Gajra Raja Medical College, Gwalior.

${ }^{2}$ Assistant Professor, Department of Obstetrics and Gynaecology, Gajra Raja Medical College, Gwalior.

${ }^{3}$ Senior Resident, Department of Obstetrics and Gynaecology, Gajra Raja Medical College, Gwalior.

\section{ABSTRACT}

\section{OBJECTIVE}

To study the maternal mortality due to PPH over last 10 years at a tertiary centre.

\section{MATERIALS AND METHODS}

Retrospective study of all maternal death due to PPH from October 2004 to September 2014 was carried out.

\section{RESULT}

There were a total of 60 maternal deaths which occurred due to PPH. Majority of maternal mortality in women with parity $>3$ (56.67\%). Unbooked cases accounted for $96.67 \%$ of maternal deaths. Most of the cases were in age group of 21-30 years. Commonest cause of maternal mortality due to PPH was atonic PPH (50\%).

\section{CONCLUSION}

Effective measures should be taken to ensure provision of antenatal care to all pregnant ladies and safe hospital deliveries, prophylactic therapeutic management of anaemia as well as availability of blood bank at the peripheral centres. Training of health personnel at the peripheral level for timely identification and referral of the high risk cases, timely availability of blood products and to ensure that all women have access to the high quality essential and emergency obstetric services along with the provisions of safe abortion, contraceptive services, and family planning counselling to reduce unplanned pregnancy.

\section{KEYWORDS}

Maternal Mortality, PPH-Postpartum Haemorrhage, Anaemia, Active Management of Third Stage of Labour, Parity.

HOW TO CITE THIS ARTICLE: Kulshreshtha S, Garg P, Dhurvey D. A retrospective study of maternal mortality due to postpartum haemorrhage over the period of last 10 years in a tertiary care centre. J. Evolution Med. Dent. Sci. 2016;5(40):2448-2451, DOI: $10.14260 /$ jemds/2016/571

\section{INTRODUCTION}

"A deep dark continuous stream of mortality- how long is this sacrifice to go on??" William Farr, the first Registrar General of England and Wales, asked this question about maternal mortality in England in 1838;(1) many years now this question still not been answered.

The International Code of Diseases (International Statistical Classification of Disease And Related Health Problems, 10 th revision)(2) defines maternal death "the death of a woman while pregnant or within 42 days of termination of pregnancy, irrespective of the duration and site of the pregnancy, from any cause related to or aggravated by the pregnancy or its management, but not from the accidental or the incidental causes."

Haemorrhage remains as one of the top 3 direct obstetric causes of maternal mortality worldwide, with most deaths occurring within 24-48 hours of delivery.(3)

Reduction of the maternal mortality ratio by three quarters by 2015 is the target for one of the eight Millennium Development Goals (MDGs) set by 189 countries in 2000.(4)

Financial or Other, Competing Interest: None.

Submission 03-03-2016, Peer Review 15-04-2016,

Acceptance 21-04-2016, Published 18-05-2016.

Corresponding Author:

Dr. Sonal Kulshreshtha

A03, Satyam Residency Satyadev Nagar,

Gandhi Road, Gwalior-474011,

Madhya Pradesh.

E-mail: drsonalkulshreshtha@gmail.com

DOI: 10.14260/jemds/2016/571
Maternal mortality is currently estimated to be 529,000 deaths per year, a number that translates into a global ratio of 400 maternal deaths per 100,000 live births. (5)

Postpartum haemorrhage is the most common cause of maternal mortality and accounts for one quarter of maternal deaths worldwide. Fig. 1.

With improvement in obstetric services, increasing public awareness for antenatal care, availability of blood bank services, better anaesthetist care, newer more potent drugs, mortality rates in our country have also gone down although at a slower pace as compared to developed world.

In a developing country like ours where malnutrition, multiparity, hypoproteinaemia during pregnancy is more prevalent and haemoglobin levels are already low, even a small amount of blood loss can also be disastrous.

What is tragic is that most of these deaths due to postpartum haemorrhage are preventable. We need to ensure that all women have access to high quality essential and emergency obstetric services along with provisions for safe abortion and contraceptive services at FRU level to reduce mortality due to unplanned pregnancies.

\section{MATERIAL AND METHODS}

This retrospective study was conducted to study the maternal mortality due to PPH over last 10 years that occurred at the Department of Obstetrics and Gynaecology, Gajra Raja Medical College, Gwalior from October 2004 to September 2014. 
RESULTS

- Majority of the death occurred till September 2010 (76.7\%) (Table No. 1).

- Most of the cases of maternal mortality due to PPH were in age group of 21-30 yrs. (Table No. 2).

- Majority of the maternal mortality was in the women with parity of 3 or more than three (Table No. 3).

- Most of the cases of maternal mortality due to PPH were the unbooked cases (Table No. 4).

- $70 \%$ of the cases were referred cases (Table No. 5).

- $75 \%$ cases were moribund at the time of admission in the Hospital (Table No. 6).

- Majority of maternal mortality due to PPH was seen in vaginal mode of delivery with 42 number of cases (Table No. 7).

- Commonest cause of maternal mortality due to PPH with was atonic PPH (Table No. 8).

- Majority of mortality was observed among the women of poor socio-economic status (73.3\%) when compared to higher socio-economic status (Table No. 9).

- In most of the cases of mortality due to PPH, duration was $<24$ hours (Table No. 10).

- In majority of the cases, blood was either not arranged or arranged after 2 hours (Table 11).

- In $71.67 \%$ cases of mortality, there was severe anaemia (Table No. 12).

- The high risk factor anaemia is associated with majority of the cases (69.86\%) (Table No. 13).

- In majority of the cases, atonic PPH was the main cause of maternal mortality due to $\mathrm{PPH}$, hence oxytocin and uterine massage used in $38.46 \%$ of the cases, followed by packing $25.64 \%$ of the cases and repair of the birth canal in $20.51 \%$ cases (Table No. 14 ).

Maternal Mortality and Morbidity: The Causes Have Changed Little Over the last few decades

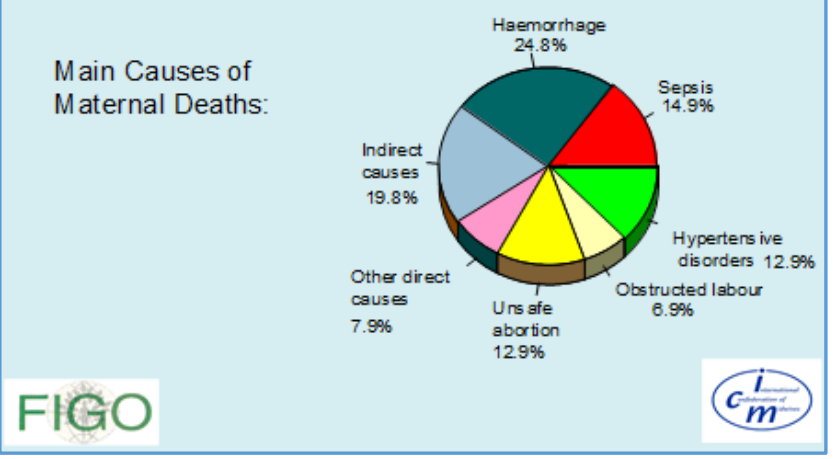

Fig. 1

\begin{tabular}{|c|c|c|}
\hline Year Wise Mortality & $\begin{array}{c}\text { No. of } \\
\text { Cases }\end{array}$ & \% \\
\hline $\begin{array}{c}\text { October-2004 To } \\
\text { September -2005 }\end{array}$ & 6 & 10 \\
\hline $\begin{array}{c}\text { October -2005 To } \\
\text { September -2006 }\end{array}$ & 2 & 3.33 \\
\hline $\begin{array}{l}\text { October -2006 To } \\
\text { September -2007 }\end{array}$ & 9 & 15 \\
\hline $\begin{array}{l}\text { October -2007 To } \\
\text { September -2008 }\end{array}$ & 7 & 11.67 \\
\hline October -2008 To & 71.67 \\
\hline
\end{tabular}

\begin{tabular}{|c|c|c|}
\hline September -2009 & 15 & 25 \\
\hline $\begin{array}{l}\text { October -2009 To } \\
\text { September -2010 }\end{array}$ & 1 & 1.67 \\
\hline $\begin{array}{l}\text { October -2010 To } \\
\text { September -2011 }\end{array}$ & 2 & 3.33 \\
\hline $\begin{array}{l}\text { October -2011 To } \\
\text { September -2012 }\end{array}$ & 4 & 6.67 \\
\hline $\begin{array}{l}\text { October -2012 To } \\
\text { September -2013 }\end{array}$ & 7 & 11.67 \\
\hline $\begin{array}{l}\text { October -2013 To } \\
\text { September -2014 }\end{array}$ & $\mathbf{6 0}$ & $\mathbf{1 0 0}$ \\
\hline Total & \multicolumn{2}{|c}{} \\
\hline Table 1: Distribution According to year wise Mortality \\
\hline
\end{tabular}

\begin{tabular}{|c|c|c|}
\hline Age (years) & No. of Cases & $\mathbf{\%}$ \\
\hline$<20$ or 20 & 7 & 11.6 \\
\hline $21-30$ & 42 & 70 \\
\hline$>30$ & 11 & 18.33 \\
\hline \multicolumn{2}{|c|}{ Table 2: Distribution According to Age } \\
\hline
\end{tabular}

\begin{tabular}{|c|c|c|}
\hline Parity & No. of Cases & \% \\
\hline P1 & 15 & 25 \\
\hline P2 & 11 & 18.3 \\
\hline$\geq$ P3 & 34 & 56.67 \\
\hline \multicolumn{2}{|c|}{ Table 3: Distribution According to Parity } \\
\hline
\end{tabular}

\begin{tabular}{|c|c|c|}
\hline Antenatal Care & No. of Cases & \% \\
\hline Booked & 2 & 3.33 \\
\hline Unbooked & 58 & 96.67 \\
\hline \multicolumn{2}{|c|}{ Table 4: Distribution According to Antenatal care } \\
\hline
\end{tabular}

\begin{tabular}{|c|c|c|}
\hline Direct or Referral & No. of Cases & $\mathbf{\%}$ \\
\hline Referral & 42 & 70 \\
\hline Direct & 18 & 30 \\
\hline \multicolumn{2}{|c|}{ Table 5: Distribution According } \\
to Direct or Referral Cases
\end{tabular}

\begin{tabular}{|c|c|c|}
\hline Condition on Admission & No. of cases & \% \\
\hline Moribund & 45 & 75 \\
\hline Stable & 15 & 25 \\
\hline \multicolumn{2}{|c|}{ Table 6: Distribution According } \\
to Condition on Admission \\
\hline
\end{tabular}

\begin{tabular}{|c|c|c|}
\hline Mode of Delivery & No. of Cases & \% \\
\hline Vaginal & 42 & 70 \\
\hline Caesarean section & 8 & 13.3 \\
\hline Laparotomy for rupture uterus & 10 & 16.6 \\
\hline
\end{tabular}

Table 7: Distribution According to mode of Delivery

\begin{tabular}{|c|c|c|}
\hline Cause of PPH & No. of Cases & $\mathbf{\%}$ \\
\hline Atonic PPH & 30 & 50 \\
\hline Atonic traumatic PPH & 7 & 11.6 \\
\hline Traumatic & 7 & 11.6 \\
\hline Rupture Uterus & 10 & 16.6 \\
\hline Uterine inversion & 2 & 3.3 \\
\hline Retained placenta & 2 & 3.3 \\
\hline DIC & 2 & 3.3 \\
\hline Table 8: Distribution According to Cause ofPPH \\
\hline
\end{tabular}




\begin{tabular}{|c|c|c|}
\hline Socioeconomic Status & No. of Cases & $\mathbf{\%}$ \\
\hline Poor & 44 & 73.33 \\
\hline Average & 12 & 20 \\
\hline Good & 4 & 6.67 \\
\hline Table 9: Distribution According to Socioeconomic Status \\
\hline
\end{tabular}

\begin{tabular}{|c|c|c|}
\hline Duration of Stay (in hrs.) & No. of Cases & $\mathbf{\%}$ \\
\hline$<1$ & 10 & 16.67 \\
\hline $1-6$ & 20 & 33.33 \\
\hline $6-24$ & 20 & 33.33 \\
\hline$>24$ & 10 & 16.67 \\
\hline \multicolumn{2}{|c|}{ Table 10: Distribution According to Duration of Stay } \\
\hline
\end{tabular}

\begin{tabular}{|c|c|c|}
\hline $\begin{array}{c}\text { Time Lapse between PPH and } \\
\text { Blood Availability }\end{array}$ & $\begin{array}{c}\text { No. of } \\
\text { Cases }\end{array}$ & $\%$ \\
\hline$<2$ hrs. & 14 & 23.34 \\
\hline$>2$ hrs. & 26 & 43.33 \\
\hline Blood not arranged & 20 & 33.33 \\
\hline $\begin{array}{c}\text { Table 11: Distribution According to Time Lapse } \\
\text { between PPH and Blood Availability }\end{array}$ \\
\hline
\end{tabular}

\begin{tabular}{|c|c|c|}
\hline Degree of Anaemia & No. of Cases & $\mathbf{\%}$ \\
\hline Mild & 9 & 15 \\
\hline Moderate & 8 & 13.33 \\
\hline Severe & 43 & 71.67 \\
\hline Table 12: Distribution According to Degree of Anaemia \\
\hline
\end{tabular}

\begin{tabular}{|c|c|c|}
\hline Associated Factors & $\begin{array}{c}\text { No. of } \\
\text { Cases }\end{array}$ & $\mathbf{\%}$ \\
\hline $\begin{array}{c}\text { Anaemia Cases (Severe / } \\
\text { Moderate) }\end{array}$ & 51 & 69.86 \\
\hline Previous 2 LSCS & 2 & 2.73 \\
\hline Previous LSCS & 3 & 4.10 \\
\hline IUD & 3 & 4.10 \\
\hline Malaria & 2 & 2.73 \\
\hline Jaundice & 4 & 5.47 \\
\hline Pre-Eclampsia & 1 & 1.36 \\
\hline Obstructed Labour & 2 & 2.73 \\
\hline Twin & 2 & 2.73 \\
\hline Grand Multiparity & 3 & 4.10 \\
\hline Total & $\mathbf{7 3}$ & $\mathbf{1 0 0}$ \\
\hline \multicolumn{2}{|c|}{$\begin{array}{l}\text { Table 13: Distribution According } \\
\text { to Associated Risk Factors }\end{array}$} \\
\hline
\end{tabular}

\begin{tabular}{|c|c|c|}
\hline Management & No. of cases & $\mathbf{\%}$ \\
\hline $\begin{array}{c}\text { Oxytocin + Uterine } \\
\text { massage }\end{array}$ & 30 & 38.46 \\
\hline Packing & 20 & 25.64 \\
\hline Repair of birth canal & 16 & 20.51 \\
\hline Internal iliac artery ligation & 4 & 5.12 \\
\hline Caesarean hysterectomy & 4 & 5.12 \\
\hline Uterine reposition & 2 & 2.56 \\
\hline $\begin{array}{c}\text { Manual removal of } \\
\text { placenta }\end{array}$ & 2 & 2.56 \\
\hline Total & $\mathbf{7 8}$ & $\mathbf{1 0 0}$ \\
\hline
\end{tabular}

Table 14: Distribution according to Management

\section{DISCUSSION}

In our study, mortality due to $\mathrm{PPH}$ is maximum in the age group of $21-30$ years which is $70 \%$.
Humaira Naz et al $2008(6)$ in their study found that $17(34 \%)$ cases of mortality due to PPH in the category of 2125 years of age. This may be a reflection of early age of marriage still prevalent and the younger age of marriage in our country is associated with the relative increased gravidity and parity at the younger age.

In the present study, parity 3 or more is associated with majority of the cases of the maternal mortality due PPH and is statistically significant $(\mathrm{P}$ value $=0.028$ ).

Munim S et al 2000(7) reported three-fold increased risk of PPH in grand multiparous woman.

In our study, 58(96.67\%) cases were unbooked and 42 $(70 \%)$ number of cases were referred.

Study done by Humaira et al.(6) in which 28(58\%) patients who developed PPH were unbooked and referred from emergency department.

Tayyab S 1996(8), Begum I 2000.(9), Wasim T 2001(10), Subtil D et al 2004(11) mentioned that most of the patients were unbooked who presented with PPH, which is the main cause of maternal mortality.

Hence, these unbooked cases presented to the hospital when they had severe, life threatening condition.

In this study, majority of mortality, 44 cases were observed among the women of poor socio-economic status $(73.3 \%)$ when compared to higher status.

In the study of Neetu Singh et al (2014),(12) majority of the cases of PPH belong to low socio-economic status $83.75 \%$. In the present study, major cause of the maternal mortality was found to be atonic PPH 30 cases (50\%) with p value $=0.93$, but is not significant, which may be due to the reason that most of the cases were referred at a very poor general condition and nowadays active management of third stage of labour (AMTSL) started at peripheral centres, but still it is the major cause among all the causes.

The main cause of PPH in the study of Neetu Singh et al.(12) was uterine atony with a frequency of $38.48 \%$ (289 cases).

In our study, maximum number of cases i.e. 50 cases had duration of stay less than 24 hours. A study done by Nishu Priya et al (2010)(13) where $54.63 \%$ of deaths occurred within 24 hours of admission.

In our study, 43(71.6\%) cases had severe anaemia.

In the study of Humaira.,(6) 44 (80\%) patients had anaemia. Out of these, $20(45.5 \%)$ had mild anaemia, $13(29.5 \%)$ had moderate and $11(25 \%)$ had severe anaemia.

In our study, $42(70 \%)$ of vaginal mode of delivery associated with the mortality due to PPH.

In the study of Humaira Naz et al.,(6) vaginal mode of delivery associated with PPH.

In our study, as the main cause of the PPH was uterine atony, uterine massage with oxytocin was required far more frequently in most of the groups.

In the present study, various risk factors associated with the PPH such as major risk factor anaemia (moderate and severe) which worsens the condition of the pregnant woman. Other than this, the risk factors which were observed in decreasing frequency were jaundice $(5.47 \%)$, previous LSCS (4.10\%), IUD (4.10\%), grand multiparity $(4.10 \%)$, malaria (2.73\%), obstructed labour $(2.73 \%)$, twins $(2.73 \%)$, previous 2 LSCS (2.73\%), preeclampsia (1.36\%).

In the studies of Hazra et al 2004.(14), Shaheen F et al.(15), Japaraj RP et al 2003.(16), it was mentioned that obstructed 
labour, pre-eclampsia, and failure to progress are all the risk factors associated with $\mathrm{PPH}$ and the frequency of $\mathrm{PPH}$ is more in the patients with APH.

\section{CONCLUSION}

The number of maternal mortality has fallen steadily in western world, but situation in part of developing world is appalling despite an increase in institutional deliveries, most pregnant women do not receive any antenatal care, and are at risk of obstetric complications. In this study, large magnitude of maternal mortality due to PPH cases may be attributed to improper management of obstetric emergencies at referring hospitals and poor, access/utilisation of health care services.

Through PPH is preventable cause of maternal mortality which can be achieved by accurate assessment of risk factors and blood loss during the delivery, with proper use of oxytocics and active management of third stage of labour. In addition, program of activities seek to expand community awareness, response and demand for quality maternal health services and should include activities within the health system to review all maternal deaths and severe morbidity and to act on lessons learned.

Early age of marriage worsens the life of women both physically as well as mentally and aggravate the present and future pregnancy. Timely monitoring of the labour such as use of partogram helps in early recognition of abnormal labour and hence helpful in timely referral, but negligence on the part of the family member regarding blood donation and society myths attached to it further exacerbate the condition. Improper habits of delivery like use of fundal pressure, mismanaged third stage of labour and control cord traction, injudicious use of uterotonic and untrained health personnel proves a great barrier.

Hence, if effective measures are taken to ensure provision of antenatal care to all pregnant ladies, safe hospital deliveries and timely referral of high risk pregnancies, complications are expected to decrease.

\section{REFERENCES}

1. Farr W. Annual report of Registrar. General of England and Wales. London 1888.

2. World health organization. International statistical classification of diseases and related health problems. ICD 10th revision, Geneva, WHO, 2004;2nd edn:2.
3. Combs CA, Murphy EL, Laros RK. Factors associated with haemorrhage in caesarean deliveries. Obstet Gynecol 1991;77(1):77-82.

4. Rosenfield A, Mained, Fredman L. Meeting MDG -5: an impossible dream? Lancet 2006;368:1132-5.

5. World health organization. The World report 2005. Attending to 136 million births every year 2005, make every mother and child count. Geneva, the WHO, 2005;61.

6. Naz G, Sarwar I, Fawad A, et al. Maternal morbidity and mortality due to primary PPH-experience at Ayub teaching hospital Abbottabad. J Ayub Med Coll Abbottabad 2008;20(2):59-65.

7. Munim S, Rahbar M, Rizvi M, et al. The effect of grand multiparity on pregnancy related complications: the agha khan university experience. J Pak Med Assoc 2000;50(2):54-8.

8. Tayyab S. Rupture of gravid uterus still an obstetrical problem: a three-year clinical analysis. J Coll Physicians Surg Pak 1996;6(3):144-7.

9. Begum I, Khan A, Jadoon N, et al. Analysis of maternal mortality in a tertiary care hospital Abbottabad. Pak J Med Res 2000;39(3):107-10.

10. Wasim T, Majrooh A, Siddiq S. Maternal mortality-one year review at Lahore general hospital. Pak Postgrad Med J 2001;12(3):113-8.

11. Subtil D, Somme A, Ardiet E, et al. Postpartum haemorrhage: frequency, consequences in terms of health status, and risk factors before delivery. J Gynecol Obstet Biol Reprod 2004;33(4):4S9-4S16.

12. Singh N, Pandey K, Sharma B, et al. A study of referral cases of postpartum haemorrhage - still an obstetrical tragedy which is largely preventable. Indian journal of research 2014;3(6):149-52.

13. Nishu Priya, Verma Ashok, Verma Suresh. Maternal mortality: ten years retrospective study. J Med Educ Res 2010;12(3):134-6.

14. Hazra S, Chilaka VN, Rajendran S, et al. Massive postpartum haemorrhage as a cause of maternal morbidity in a large tertiary hospital. J Obstet Gynaecol 2004;24(5):519-20.

15. Shaheen F, Jeen J. Postpartum haemorrhage: still a challenge. J Rawal Med Coll 2003;7:77-81.

16. Japraj RP, Raman S. Segstaken-Blakemore tube to control massive postpartum haemorrhage. Med J Malaysia 2003;58(4):604-7. 